\title{
Capsule Commentary on Dzeng et al., Moral Distress Amongst American Physician Trainees Regarding Futile Treatments at the End of Life: a Qualitative Inquiry
}

\author{
Neda Ratanawongsa, M.D., M.P.H. \\ UCSF Center for Vulnerable Populations, San Francisco, CA, USA.
}

J Gen Intern Med 31(1):108

DOI: $10.1007 / \mathrm{s} 11606-015-3535-8$

(c) Society of General Internal Medicine 2015

$\mathrm{D}$ zeng et al. ${ }^{1}$ explore a potentially role-defining experience of internal medicine training: providing care one believes to be futile near the end of life. Using interviews at three academic institutions, the authors solicited residents' and fellows' experiences providing treatments that provoked moral distress or conflicted with their moral beliefs. Emergent themes revealed that trainees viewed such experiences as "torture," both for the patients whose suffering they were powerless to alleviate and to trainees themselves, who were left feeling powerless, numb, and cynical.

The study is not meant to explore the prevalence of futility, but rather to delve deeply into how trainees process and cope with this professional trauma. The recruitment strategy may have affected sampling bias in two ways. Residents with profoundly negative experiences may have been more likely to participate, and the interviews themselves may have offered a venue to reflect on lingering emotions. Alternatively, those with more severe distress may have been underrepresented, if they felt concerned about relieving these experiences or about the safety in speaking honestly. Still, the findings raise important considerations for medical educators.

The study also goes beyond questions about whether trainees can define futility, focusing on how they maintain their sense of self during arduous training years. While the definitions continuously evolve through societal and legal debate, ${ }^{2}$ these ethical challenges exact a toll. Potential solutions may be found in relationship-centered care (RCC). Emphasizing the importance of clinician authenticity, RCC recognizes that we bring our own emotions and values into our relationships with patients, family members, and team members, and acknowledges how we are shaped by these relationships. ${ }^{3}$ Training programs and health care systems need infrastructure to support honest discussions about such challenging cases and the emotions they evoke, whether during rounds with palliative care consultants or mentored family meetings. Such venues may alleviate trainee suffering - and perhaps the unstated suffering of their attendings - by allowing all to express their doubts and grief over treatment decisions. As programs adopt essential palliative care competencies, ${ }^{4}$ the heart of these skills remain the mindful practice and self-care that allow clinicians to negotiate and navigate these tough decisions. ${ }^{5}$

Corresponding Author: Neda Ratanawongsa, M.D., M.P.H.; UCSF Center for Vulnerable Populations, San Francisco, CA, USA (e-mail: ratanawongsan@medsfgh.ucsf.edu).

Compliance with Ethical Standards:

Conflict of Interest: The author declares that she does not have a conflict of interest.

\section{REFERENCES}

1. Dzeng E, Colaianni A, Roland M, Levine D, Kelly MP, Barclay S, Smith TJ. Moral distress amongst American physician trainees regarding futile treatments at the end of life: a qualitative inquiry. J Gen Intern Med. 2015. doi:10.1007/s11606-015-3505-1.

2. Misak CJ, White DB, Truog RD. Medical futility: a new look at an old problem. Chest. 2014;146(6):1667-72.

3. Beach MC, Inui T. The relationship-centered care research network. relationship-centered care: a constructive reframing. J Gen Intern Med. 2006;21(Suppl 1):S3-8.

4. Schaefer KG, Chittendon EH, Sullivan AM, Periyakoil VS, Morrison LJ, Carey EC, Sanchez-Reilly S, Block SD. Raising the bar for the care of seriously ill patients: results of a national survey to define essential palliative care competencies for medical students and residents. Acad Med. 2014;89(7): 1024-31.

5. Epstein RM. Mindful practice. JAMA. 1999;282(9):833-9.

Published online October 30, 2015 